АКТУАЛИЗАЦИЯ ПОЗИЦИЙ ГЛИФЛОЗИНОВ В АЛГОРИТМАХ ЛЕЧЕНИЯ

ПАЦИЕНТОВ С САХАРНЫМ ДИАБЕТОМ 2 ТИПА И ХРОНИЧЕСКОЙ БОЛЕЗНЬЮ

ПОЧЕК: НОВЫЕ ПАТОГЕНЕТИЧЕСКИЕ МЕХАНИЗМЫ И ДАННЫЕ СУБАНАЛИЗОВ КРУПНЫХ РАНДОМИЗИРОВАННЫХ КОНТРОЛИРУЕМЫХ ИССЛЕДОВАНИЙ

() О.Ю. Сухарева*, 3.Т. Зураева, М.Ш. Шамхалова

Национальный медицинский исследовательский центр эндокринологии, Москва

Результаты ряда крупных международных исследований по оценке влияния ингибиторов натрийглюкозного котранспортера 2-го типа (SGLT2) на сердечно-сосудистый риск продемонстрировали нефропротективный потенциал этих препаратов. Канаглифлозин в исследовании CREDENCE, которое было первым исследованием с первичным фокусом на оценке нефропротективных свойств глифлозинов, убедительно показал возможность замедления прогрессирования почечной патологии. В статье обобщены результаты последовавших субанализов CREDENCE: эффективность канаглифлозина в зависимости от исходного уровня расчетной скорости клубочковой фильтрации (рСКФ); эффекты у лиц с рСКФ <30 мл/мин/1,73 м²; влияние на развитие и течение анемии; влияние на уровень калия в крови; эффекты в отношении сердечной недостаточности и сердечно-сосудистой смертности. С учетом доказанных преимуществ современные алгоритмы лечения пациентов с сахарным диабетом 2 типа и хронической болезнью почек отдают приоритет использованию глифлозинов. Канаглифлозин является препаратом с относительно низким соотношением селективности к SGLT1/SGLT2. Описаны механизмы, опосредованные ингибированием SGLT1 транспорта в почке и в кишечнике, что, помимо уменьшения постпрандиальной гликемии, возможно, имеет дополнительный потенциал для нефропротекции.

КЛЮЧЕВЫЕ СЛОВА: сахарный диабет 2 типа; хроническая болезнь почек; SGLT1; SGLT2; SGLT2 ингибиторы; глифлозины; канаглифлозин; CREDENCE; нефропротекция

\title{
GLIFLOZINS POSITION UPDATE IN THE TREATMENT ALGORITHMS FOR PATIENTS WITH TYPE 2 DIABETES MELLITUS AND CHRONIC KIDNEY DISEASE: NEW PATHOGENETIC MECHANISMS AND DATA FROM SUBANALYSES OF THE LARGE RANDOMISED CONTROL TRAILS
}

(c) Olga Yu. Sukhareva*, Zamira T. Zuraeva, Minara Sh. Shamkhalova

Endocrinology Research Centre, Moscow, Russia

The series of the cardiovascular outcome trails have demonstrated the nephroprotective properties of the gliflozins. Canagliflozin in the CREDENCE, which was the first study with a primary focus on the evaluation of the nephroprotective properties of gliflozin, have demonstrated the possibility to slow the progression of the renal disease. The paper summarizes the additional data from the CREDENCE trail: assessment of the efficacy of canagliflozin by initial eGFR; efficacy in individuals with GFR $<30 \mathrm{ml} / \mathrm{min} / 1.73 \mathrm{~m}^{2}$; long-term effects of canagliflozin on anaemia-related outcomes; effects of canagliflozin on serum potassium; effects on heart failure and cardiovascular mortality. There are discussed the current treatment algorithms for patients with type 2 diabetes and CKD where using of gliflozins is a priority option. Canagliflozin is a drug with a relatively low ratio of SGLT1/SGLT2 selectivity. The effects of the inhibition of SGLT1 transport in the kidney and in the intestine are described and their additional influence on reducing of the postprandial glycemia and additional nephroprotection.

KEYWORDS: type 2 diabetes mellitus; chronic kidney disease; SGLT1; SGLT2; SGLT2 inhibitors; gliflozins; canagliflozin; CREDENCE; nephroprotection

Еще во II веке н.э. греческий физиолог Аратеус постулировал, что причиной сахарного диабета (СД) является «расстройство» в работе почек. Но теперь мы знаем, что все гораздо сложнее. Поддержание нормального гомеостаза глюкозы определяется высокой степенью интеграции печени, мышц, адипоцитов, поджелудочной железы и нейроэндокринной системы, обеспечивающих стабильный уровень гликемии [1]. Необходимость поддержания постоянного уровня глюкозы в крови связана с тем, что для многих тканей глюкоза является основным (нервная ткань), а для некоторых - единственным (эритроциты) источником энергии. Высвобождение глюкозы является результатом одного из двух процессов: гликогенолиза и глюконеогенеза. Гликогенолиз включает 
расщепление гликогена на глюкозо-б-фосфат и его последующий гидролиз глюкозо-б-фосфатазой до свободной глюкозы. Распад печеночного гликогена приводит к высвобождению глюкозы, тогда как распад мышечного гликогена приводит к высвобождению лактата вследствие различного представительства ферментных систем в печени и мышцах.

Только два органа в организме человека - печень и почка - обладают достаточной активностью глюконеогенного фермента глюкозо-6-фосфатазы, что позволяет им высвобождать глюкозу в кровоток в результате глюконеогенеза. Почки могут быть таким же важным глюконеогенным органом, как и печень [2]. Впервые экспериментальное подтверждение глюконеогенеза в почках было получено в 1938 г. в работах Н. Bergman и соавт. на клэмп-моделях у гепатоэктомированных и нефрэктомированных кроликов [3].

Почечный глюконеогенез осуществляется в основном в проксимальных канальцах в коре почек, и этот процесс регулируется инсулином и катехоламинами (адреналином). Инсулин подавляет глюконеогенез непосредственно, уменьшает доступность субстратов глюконеогенеза, таких как лактат, глютамин и глицерол, а также высвобождение глюкозы. При повышении инсулинорезистентности снижается этот супрессивный эффект гормона на высвобождение глюкозы. Адреналин стимулирует почечный глюконеогенез, стимулирует высвобождение глюкозы, ингибирует секрецию инсулина, повышает доставку субстратов глюконеогенеза. Почки могут компенсировать, по крайней мере частично, нарушенное высвобождение глюкозы в печени и вносить свой вклад в чрезмерное высвобождение глюкозы, наблюдаемое при СД 2 типа (СД2) [4]. Необходимы дальнейшие исследования, чтобы прийти к единому мнению о вкладе почек в общее высвобождение глюкозы, для оценки эффектов доступности субстратов, фармакологических агентов, влияющих на высвобождение глюкозы, и оценить роль почек в различных патологических состояниях (например, почечной недостаточности, печеночной недостаточности, сепсисе и старении).

Еще одни важные механизмы, с помощью которых почки влияют на гомеостаз глюкозы, - ее поглощение из циркуляции и реабсорбция из мочи, профильтрованной почечными клубочками. Это адаптивные механизмы, обеспечивающие достаточную энергию, доступную во время периода голодания. У здоровых лиц фактически вся глюкоза, профильтрованная клубочками (160-180 г), реабсорбируется проксимальными канальцами и возвращается в циркуляцию, таким образом, глюкоза не экскретируется с мочой.

Реабсорбция глюкозы из гломерулярного фильтрата опосредуется протеинами глюкозо-натриевого котранспортера (SGLT), и этот процесс независим от инсулина, в отличие от действия стимулирующего глюкозного транспортера GLUT4, ответственного за поглощение глюкозы инсулинчувствительными тканями, такими как жировая и мышечная.

SGLT - это семейство мембраносвязанных протеинов, активно транспортирующих глюкозу против градиента концентрации с необходимым источником энергии, доставляемым натриевой помпой. Такой вид транспорта называют вторично активным, или симпортом.

Семейство SGLT имеет субстратами глюкозу, галактозу, маннозу, и его представители распределены в различных органах и тканях (почки, головной мозг, сердце, щитовидная железа, кишечник, печень, легкие, поджелудочная железа и др.). Около 90\% профильтрованной почками глюкозы реабсорбируется в пограничных щеточных клетках первого сегмента проксимальных извилистых канальцев с помощью SGLT2 - низкоаффинного, но очень емкого транспортера и 10\% - в дистальном сегменте с помощью SGLT1 - высокоаффинного, но малоемкого транспортера в сегменте S3. Последний также широко экспрессирует в тонком кишечнике, где он играет существенную роль в абсорбции глюкозы.

Возможны различные ситуации «несработки» механизма реабсорбции, обусловленные генными мутациями (семейная почечная глюкозурия, глюкозо-галактозная мальабсорбция). В первом случае пациенты редко страдают от гипогликемии и гиповолемии. При их описании не упоминается повышенный риск урогенитальных инфекций. Во втором случае развивается выраженная диарея у новорожденных. Однако у взрослых лиц появляется толерантность к глюкозе, возможно, вследствие развития гастроинтестинальной флоры, содействующей ее метаболизму [5].

Всасывание глюкозы почками в постабсорбционном периоде повышается у лиц с СД2 в сравнении со здоровыми вследствие повышенной экспрессии и активности SGLT2. Продемонстрировано также повышение экспрессии SGLT1 в кишечном тракте у лиц с диабетом. Высокое содержание глюкозы приводит к усилению экспрессии SGLT-1 в альфа-клетках. Сигнальный путь, начинающийся с SGLT-1 и включающий образование активных форм кислорода (ROS), может объяснить феноменальное повышение секреции глюкагона в этих условиях механизмом, зависящим от транспорта, а не метаболизма глюкозы [6].

Роль активности SGLT2 в развитии кардиальной и почечной патологии посредством интраренальных, метаболических, нейрососудистых эффектов у пациентов с СД2 хорошо изучена. Более того, возможности ее ингибиции, исследованные в рандомизированных клинических исследованиях (РКИ) [7], изменили парадигму фармакологии сердечно-сосудистой и ренальной патологии. Менее изученной и недооцененной остается роль активности SGLT1.

В экспериментальной работе на мышах показан новый механизм гиперфильтрации (основной фактор развития диабетической нефропатии), вызванной повышенной экспрессией и активностью NO-синтазы под влиянием SGLT1, обнаруженного в области плотного пятна (macula densa) при острой гипергликемии. NO, генерируемый NO-синтазой в macula densa, является основным модулятором ответа канальцево-клубочковой обратной связи с ослаблением сосудосуживающего эффекта приносящей артериолы и повышением скорости клубочковой фильтрации (СКФ) [8]. Примечательно, что переносчиком глюкозы в просвете macula densa с наивысшим уровнем транскрипции был именно SGLT1 (рис. 1). 


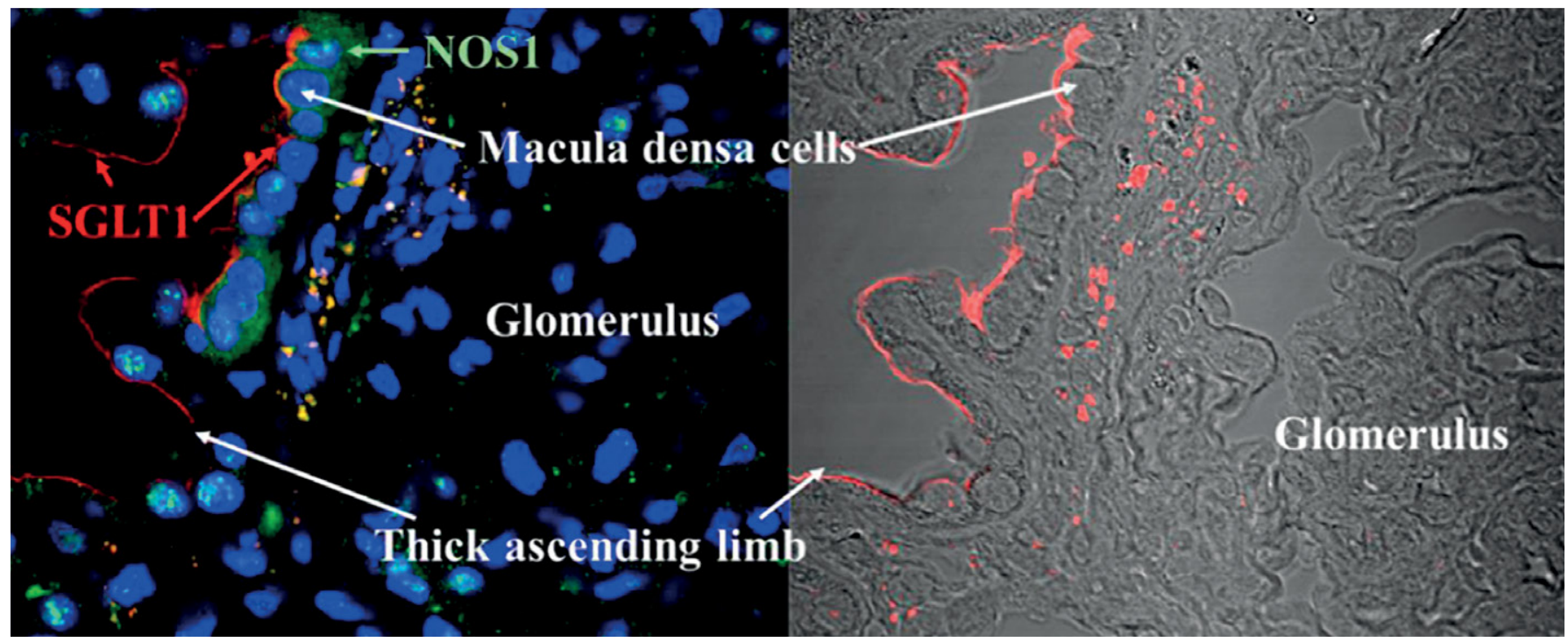

Рисунок 1. Натрий-глюкозный котранспортер 1-го типа и NO-синтаза в клетках почечных канальцев в области macula densa [8].

Поэтому ингибиция только SGLT2 не может в полной мере контролировать гиперфильтрацию со всеми последствиями (рис. 2).

Кроме того, было продемонстрировано, что мыши с делецией NO-синтазы (nNOS) не развивают глюкозо-индуцированную гиперфильтрацию. Следует отметить, что в эксперименте участвовали мыши без нарушения углеводного обмена. В этой работе подтверждена экспрессия SGLT1 в macula densa человека в образцах биопсии почки при окрашивании методом двойной иммунофлуоресценции. Будущие исследования должны быть проведены с диабетическими моделями животных для определения значения этого пути развития почечной патологии. Новые данные позволяют рассчитывать на дополнительные возможности совместного ингибирования SGLT1 и SGLT2 не только в контроле гликемии, но и нефропротекции при СД2 [9] (рис. 3).
Фармакологическое ингибирование натрий-глюкозного котранспорта - основной механизм действия препаратов группы глифлозинов и в течение последних нескольких лет доступный метод лечения СД2.

Одним из важных различий, характеризующих различных представителей класса глифлозинов, является селективность по отношению к SGLT2/SGLT1 транспортерам. Этот показатель составляет 2500 для эмпаглифлозина, 2000 - для эртуглифлозина, $1200-$ для дапаглифлозина, 254-860 - для ипраглифлозина и 250 - для канаглифлозина $[10,11]$. Таким образом, канаглифлозин обладает наименьшей, а эмпаглифлозин наибольшей селективностью в отношении ингибирования SGLT2/SGLT1 по сравнению с другими используемыми в РФ глифлозинами.

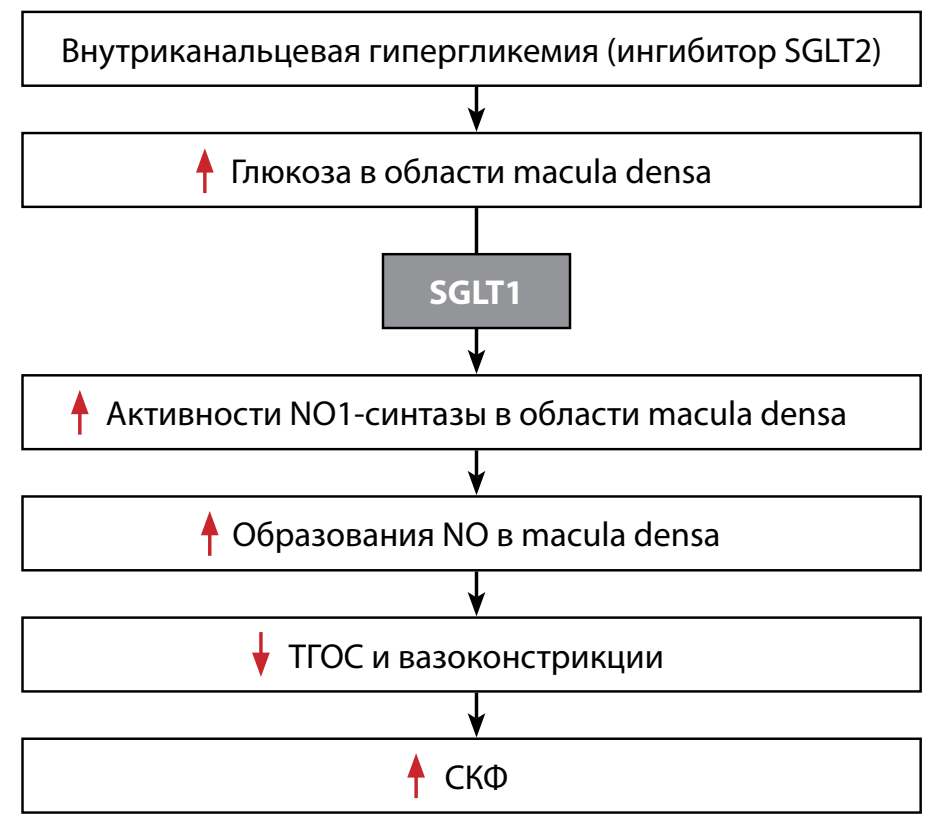

Рисунок 2. Механизм клубочковой гиперфильтрации при внутриканальцевой гипергликемии (ocь SGLT1-NOS1-TrOC в macula densa может опосредовать клубочковую гиперфильтрацию при внутриканальцевой гипергликемии) [8].

Примечание. SGLT2 - натрий-глюкозный котранспортер 2 типа; SGLT1 - натрий-глюкозный котранспортер 1 типа; macula densa - плотное пятно; ТГОС - тубулогломерулярная обратная связь; СКФ - скорость клубочковой фильтрации. 


\section{Гипергликемия}

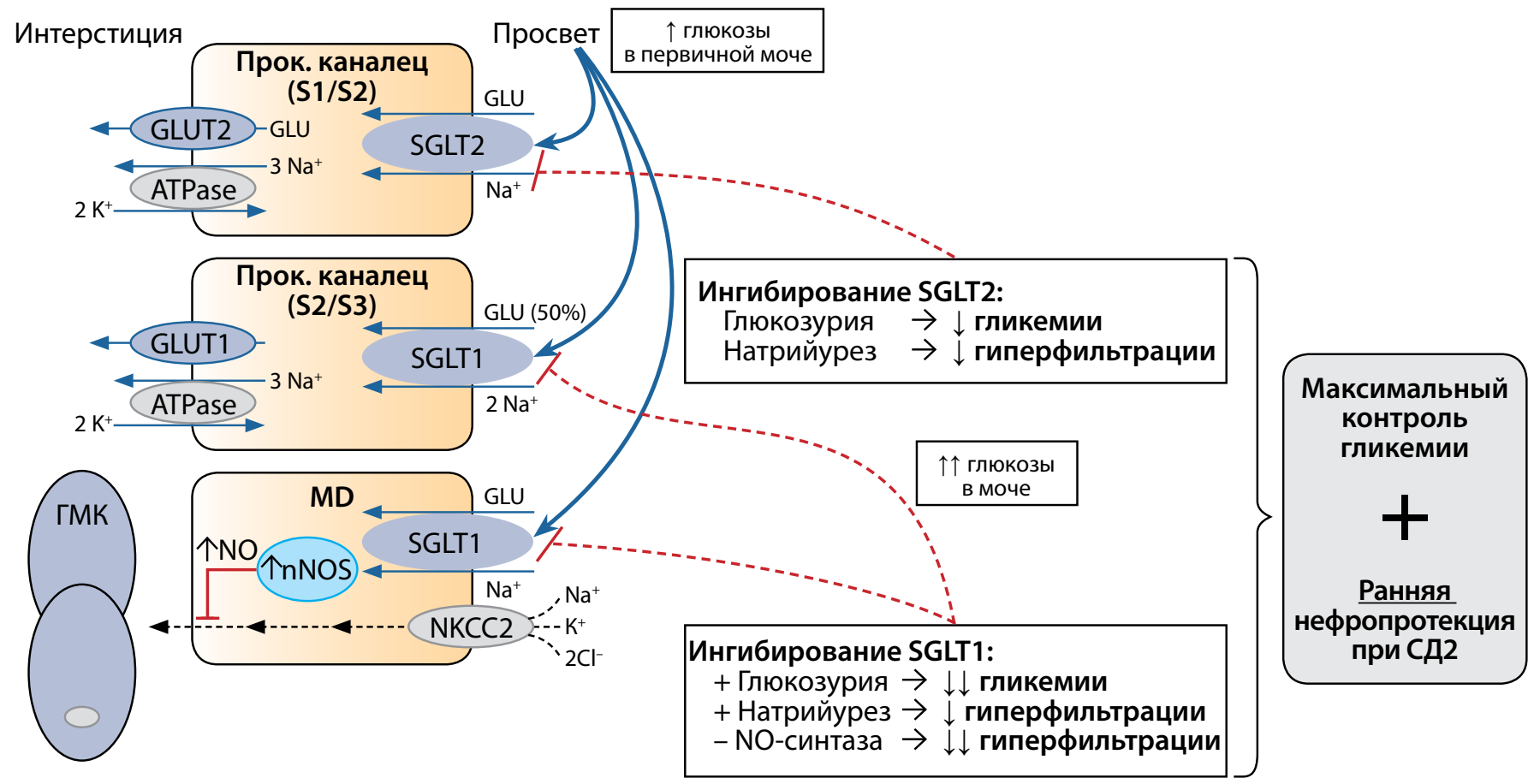

Рисунок 3. Эффекты совместного ингибирования натрий-глюкозных котранспортеров 1-го и 2-го типа [9]. Примечания: SGLT — натрий-глюкозный котранспортер, GLU — глюкоза, MD — macula densa (Плотное пятно)

\section{ВОЗМОЖНЫЕ НЕФРОПРОТЕКТИВНЫЕ ЭФФЕКТЫ глИФЛОзИНОВ}

Вышеописанные механизмы, включающиеся при условии дополнительного ингибирования SGLT1 и потенциально обеспечивающие усиление нефропротективного действия препарата, являются дополнением к многократно описанному каскаду реакций, запускаемых фармакологически индуцированными глюкозурией и умеренным натрийурезом (возможно, преходящим) на фоне приема ингибитора SGLT2, который обеспечивает разнонаправленные механизмы нефропротекции. Предполагаемые нефропротективные эффекты глифлозинов подробно освещены в научной литературе [12-20]. Ренопротективные эффекты глифлозинов можно условно разделить на прямые (реализующиеся непосредственно в почке) и непрямые (связанные с улучшением гликемического профиля, снижением массы тела, артериального давления, концентрации мочевой кислоты в крови и т.д.).

Одним из основных нефропротективных свойств глифлозинов признается возможность снижения внутриклубочкового давления. На фоне приема препаратов происходит увеличение концентрации натрия в просвете канальца в области macula densa, за этим следует сужение приносящей артериолы клубочка вследствие снижения выработки аденозина (восстановление нарушенной канальцево-клубочковой обратной связи), ослабление гиперфильтрации и в результате - снижение интрагломерулярного давления. Помимо этого, для глифлозинов показана возможность блокирования натрий-водородного обменника NHE3, что также может влиять на реабсорбцию натрия в проксимальном почечном канальце; уменьшение тубулотоксичности глюкозы и тубулярной гипертрофии, уменьшение оксидативного стресса, выраженности процессов воспаления и фиброза, снижение активации ренин-ангиотензин-альдостероновой системы
(PAAC), уменьшение почечной потребности в кислороде и гипоксии (в том числе посредством увеличения выработки эритропоэтина) и т.д. При этом доказано, что нефропротективные эффекты реализуются вне связи с сахароснижающим действием.

\section{ИНГИБИТОРЫ SGLT2, ДОКАЗАВШИЕ РЕНАЛЬНЫЕ ПРЕИМУЩЕСТВА В КРУПНЫХ РКИ ПО ОЦЕНКЕ СЕРДЕЧНО-СОСУДИСТОГО РИСКА САХАРОСНИЖАЮЩИХ ПРЕПАРАТОВ}

Большинство представителей класса глифлозинов имеют завершенные крупные РКИ по оценке их влияния на сердечно-сосудистый риск, в которых почечные исходы оценивались в статусе вторичных конечных точек.

В исследовании EMPA-REG OUTCOME (98\% пациентов с атеросклеротическими сердечно-сосудистыми заболеваниями (АССЗ)) применение эмпаглифлозина по сравнению с плацебо снижало риск развития или прогрессирования нефропатии (сочетание прогрессирования показателя соотношения альбумин/креатинин (А/Kр) в моче до >300 мг/г, удвоения креатинина в сыворотке, терминальной почечной недостаточности (ТПН) или смерти от почечных причин) на 39\% и риск удвоения креатинина в сыворотке, сопровождающегося снижением расчетной СКФ (рСКФ) <45 мл/мин/1,73 м² на 44\% [21, 22].

Канаглифлозин в программе CANVAS и CANVAS-R (65\% участников с АСС3 и 35\% с факторами риска) снижал риск прогрессирования альбуминурии на $27 \%$ и риск снижения рСКФ, достижения ТПН или смерти от почечных причин на 40\% в сравнении с плацебо [23].

Применение дапаглифлозина в исследовании DECLARE-TIMI 58 (40\% участников с ACC3 и 60\% с факторами риска) сопровождалось снижением показателя комбинированной точки почечных исходов (снижение 
рСКФ $\geq 40 \%$ до $<60$ мл/мин/1,73 м², развитие ТПН или смерть от почечных причин) на $47 \%$ по сравнению с плацебо [24].

Эртуглифлозин в исследовании VERTIS CV (99,9\% участников с АСС3) после модификации исследовательской вторичной ренальной точки (исходно оценивалась как удвоение креатинина, инициация заместительной почечной терапии, смерть от почечных причин) и включения оценки рСКФ (стойкое снижение на $40 \%$ от исходного уровня) показал сходные с вышеперечисленными препаратами почечные преимущества [25].

Лимитирующим фактором для этих данных является то, что общее количество случаев почечных исходов в этих РКИ было относительно небольшим, а их оценка не являлась первичным фокусом исследования. Тем не менее данные метаанализа показали, что независимо от наличия ACC3 или только факторов риска терапия ингибиторами SGLT2 сопровождается дополнительными преимуществами (снижение госпитализации по поводу сердечной недостаточности (СН) или прогрессирования хронической болезни почек (ХБП) у лиц с высоким риском АСС3) [26].

\section{РЕЗУЛЬТАТЫ КРУПНЫХ РКИ ПО ОЦЕНКЕ НЕФРОПРОТЕКТИВНЫХ ЭФФЕКТОВ ГЛИФЛОЗИНОВ}

Знаковой вехой в упрочении позиций ингибиторов SGLT2 в современных терапевтических алгоритмах стало исследование CREDENCE (Canagliflozin and Renal Events in Diabetes with Established Nephropathy Clinical Evaluation). Именно исследование CREDENCE стало первым РКИ, спланированным для оценки влияния препарата класса глифлозинов на почечные исходы у пациентов с СД2 и диабетической нефропатией [27].

Популяция исследования ( $\mathrm{n}=4401$ участников) аккумулировала только пациентов с высоким и очень высоким риском сердечно-сосудистых и почечных событий, что обеспечивалось основными критериями включения: соотношение A/Kр в моче >300-5000 мг/г и рСКФ 30-<90 мл/мин/1,73 м² на фоне блокады РАAС: стабильный прием ингибитора ангиотензин-превращающего фермента (АПФ) или антагониста рецепторов к ангиотензину (АРА) в максимально разрешенной либо в максимально переносимой дозе. Исходные средние характеристики популяции: возраст 63 года, гликированный гемоглобин $\left(\mathrm{HbA}_{1 c}\right)$ 8,3\%, артериальное давление (АД) - 140/78 мм рт. Ст., рСКФ - 56,2 мл/мин/1,73 м², медиана соотношения А/Кр в моче - 927 мг/г (105 мг/ммоль), 34\% женщины, 50\% участников имели в анамнезе АСС3.

Первичная конечная точка была комбинированной и включала композитную ТПН (диализ, трансплантация почки или стойкое снижение рСКФ <15 мл/мин/1,73 м²), удвоение показателя креатинина в сыворотке крови или смерть от почечных или сердечно-сосудистых причин.

Исследование было остановлено досрочно Комитетом по мониторингу безопасности данных в связи с однозначным достижением первичной конечной точки, медиана наблюдения составила 2,62 года.

Риск событий первичной конечной точки был на $30 \%$ ниже на фоне применения канаглифлозина
100 мг в день по сравнению с плацебо с частотой событий 4,2 и 61,2/1000 пациенто-лет наблюдения соответственно (ОР 0,70; 95\% ДИ 0,59-0,82; $\mathrm{P}=0,00001)$.

При применении канаглифлозина 100 мг по сравнению с плацебо относительный риск специфической композитной почечной конечной точки (ТПН, удвоения уровня креатинина в крови или смерти от почечных причин) был ниже на 34\% (ОР 0,66; 95\% ДИ 0,53-0,81; P<0,001), относительный риск ТПН был ниже на 32\% (ОР 0,68; $95 \%$ ДИ 0,54-0,86; P=0,002). Также в группе канаглифлозина был ниже риск сердечно-сосудистой смерти (ССС), инфаркта миокарда или инсульта (ОР 0,80; 95\% ДИ 0,67-0,95; $\mathrm{P}=0,01)$ и госпитализации по поводу СН (ОР 0,61; 95\% ДИ 0,47-0,80; $\mathrm{P}<0,001$ ) [27].

Результаты исследования CREDENCE были с большим энтузиазмом восприняты профессиональным сообществом, особенно с учетом того, что после подтверждения нефропротективных эффектов блокады РААС около двух десятилетий в терапевтическом арсенале не появлялось никаких новых фармакологических агентов, позволяющих эффективно замедлить прогрессирование поражения почек при СД $[28,29]$. Выраженность кардио- и нефропротективных эффектов канаглифлозина в популяции исследования CREDENCE ярко иллюстрируется показателями NNT (Number Needed to Treat), т.е. числом больных, которых необходимо лечить определенным методом в течение определенного времени, чтобы достичь определенного эффекта или предотвратить неблагоприятный исход у одного пациента. Для первичной конечной точки показатель NNT составил 22 (95\% ДИ 15-38); для композитной почечной конечной точки NNT 28 (95\% ДИ 19-54); для ТПН NNT составил 43 (95\% ДИ 26-121). Также эти показатели были оценены для СН: NNT составил 46 (95\% ДИ 29-124) и комбинированной точки ССС, инфаркт миокарда или инсульт: NNT 40 (95\% ДИ 23-165) [27].

Следующим важным этапом в усилении позиций глифлозинов как препаратов, способных радикально улучшить прогноз при почечной патологии, стали опубликованные в 2021 г. результаты исследования DAPA-CKD ( $n=4304$ пациента) [30]. Как и в исследовании CREDENCE, критерием включения была выраженная альбуминурия (соотношение А/Kр в моче 200-5000 мг/г) в сочетании с показателем рСКФ 25-75 мл/мин/1,73 м². Однако, помимо пациентов с СД2 (67,5\%), в исследование были включены и пациенты с ХБП недиабетического генеза. Исследование также было остановлено досрочно в связи с однозначным достижением эффективности.

Через 2,4 года события первичной конечной точки произошли у 197 из 2152 пациентов (9,2\%) в группе терапии дапаглифлозином и у 312 из 2152 участников (14,5\%) в группе плацебо (OP 0,61; 95\% ДИ 0,51-0,72; P<0,001; NNT для предупреждения 1 события первичной конечной точки 19 (95\% ДИ 15-27)). Для комбинированной почечной конечной точки (снижение рСКФ >50\%, ТПН или смерть от почечных причин) ОР 0,56 (95\% ДИ 0,45-0,68; Р<0,001), для комбинированной точки «госпитализация по поводу СН/CСС» ОР составил 0,71 (95\% ДИ 0,55-0,92; $\mathrm{P}=0,009)$.

Риск общей смертности снизился на $31 \%$ (OP 0,69; 95\% ДИ 0,53-0,88; $\mathrm{P}=0,004)$. При этом эффекты дапаглифлозина не различались у лиц с диабетом и без него, что является основанием для внедрения глифлозина и в схемы лечения пациентов с ХБП без СД2. 


\section{СУБАНАЛИЗЫ ИССЛЕДОВАНИЯ CREDENCE}

За последние 2 года опубликован ряд субанализов исследования CREDENCE, которые дали информацию по очень важным для клиницистов вопросам, касающимся ожидаемых эффектов при применении ингибиторов SGLT2 у пациентов с серьезно скомпрометированной почечной функцией на примере канаглифлозина в крупном РКИ с соответствующим дизайном.

\section{Эффекты канаглифлозина в зависимости от уровня исходной рСКФ}

По мере вхождения глифлозинов в клиническую практику одними из самых обсуждаемых были ситуации их возможного применения, особенно инициации, у лиц с относительно низкими показателями рСКФ, так как в большинстве исследований для этих препаратов было показано снижение этого показателя в начале применения. Это снижение достигает 5 мл/мин/1,73 м² и является обратимым (восстановление рСКФ происходит в среднем через 4 нед применения). Наиболее вероятным объяснением этого эффекта является снижение внутриклубочкового давления после восстановления канальцево-клубочковой обратной связи и снижения гиперфильтрации.

M. Jardine и соавт. в 2020 г. выполнили субанализ исследования CREDENCE с целью оценить эффективность канаглифлозина в отношении почечных и сердечно-сосудистых событий в зависимости от исходной рСКФ участников [31].

Исходный дизайн исследования предполагал, что большая часть пациентов (около 60\%) будут иметь рСКФ $<60$ мл/мин/1,73 м², аккумулируя высокую долю пациентов свысоким риском сердечно-сосудистых и почечных событий.

На этапе скрининга участники распределились следующим образом:
рСКФ 30-<45 мл/мин/1,73 м² - 1313 участников (30\%); рСКФ 45-<60 мл/мин/1,73 м² - 1279 пациентов (29\%); рСКФ 60-<90 мл/мин/1,73 м² - 1809 пациентов (41\%).

Анализ данных показал, что прием канаглифлозина 100 мг обеспечивал сопоставимые преимущества в отношении снижения риска почечных и сердечно-сосудистых исходов среди всех подгрупп рСКФ, включая участников с исходной рСКФ (все р-взаимодействия 0,11).

При этом у участников с более низкими исходными показателями рСКФ (<60 мл/мин/1,73 м², то есть фактически характеризующихся более высоким риском) были продемонстрированы большие абсолютные преимущества применения канаглифлозина. Так, по мере снижения рСКФ количество событий, учтенных для анализа, объяснимо возрастало.

Снижение рСКФ в группе плацебо происходило со средней скоростью 4,59 мл/мин/1,73 м² в год со сходными темпами снижения во всех подгруппах. Применение канаглифлозина при инициации терапии приводило к некоторому снижению рСКФ (наименее выраженному у лиц с исходной рСКФ 30-<45 мл/мин/1,73 м²) с последующей стабилизацией и далее более медленным снижением рСКФ по сравнению с плацебо во всех подгруппах (различия составили $>50 \%$ во всех подгруппах).

Упациентов представляющей особый интересподгруппы с рСКФ 30-<45 мл/мин/1,73 м² применение канаглифлозина привело к начальному снижению СКФ на 2,03 мл/мин/1,73 м², но после этого на фоне приема канаглифлозина снижение рСКФ происходило медленнее по сравнению с группой плацебо (-1,72 vs -4,33 мл/мин/1,73 м²); разница между группами составила 2,61 мл/мин/1,73 м². Применение канаглифлозина сопровождалось замедлением темпов снижения рСКФ на 60 и 65\% в подгруппах с исходной рСКФ 30-<45 мл/мин/1,73 м² и 45-<60 мл/мин/1,73 м² соответственно. Динамика изменения рСКФ в различных подгруппах представлена на рис. 4.

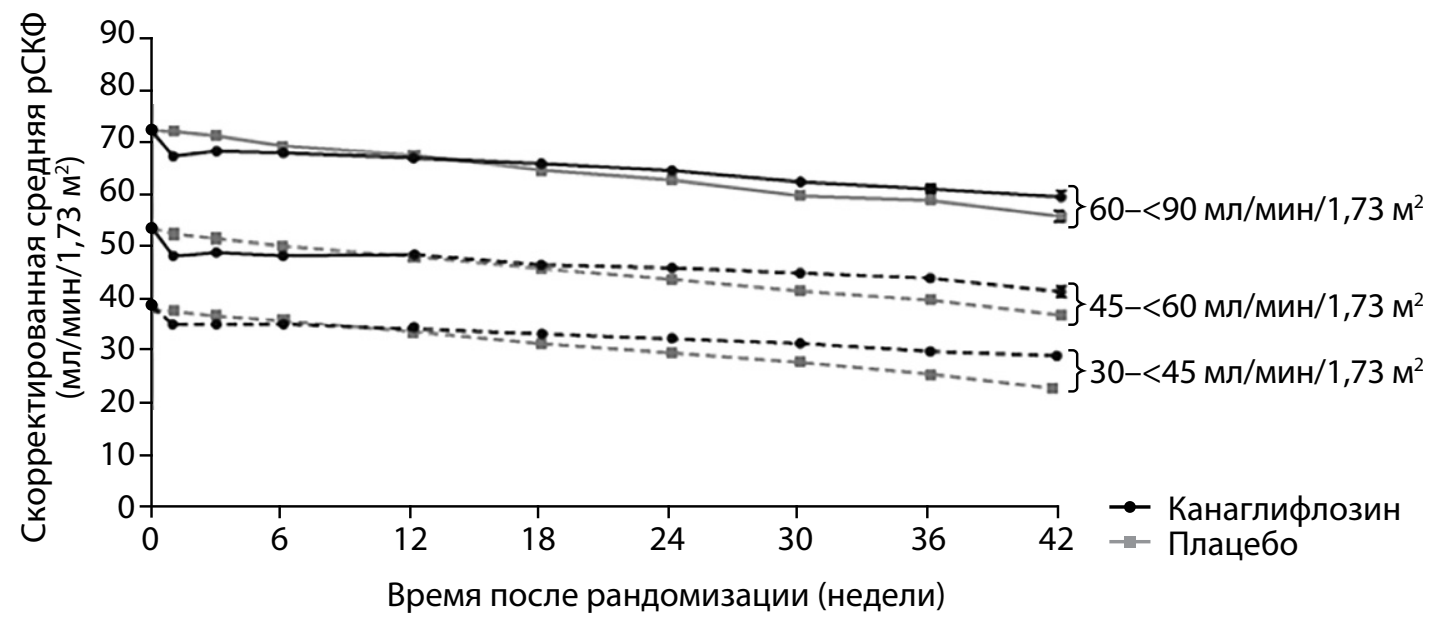

Число пациентов

\begin{tabular}{llllllllll}
\hline \multirow{2}{*}{$60-<90$} & Канаглифлозин & 899 & 833 & 803 & 758 & 710 & 490 & 288 & 98 \\
& Плацебо & 895 & 829 & 801 & 755 & 679 & 471 & 270 & 100 \\
\hline \multirow{2}{*}{$45-<60$} & Канаглифлозин & 635 & 589 & 563 & 531 & 490 & 333 & 202 & 80 \\
& Плацебо & 635 & 575 & 535 & 483 & 435 & 278 & 168 & 58 \\
\hline \multirow{2}{*}{$30-<45$} & Канаглифлозин & 645 & 583 & 553 & 493 & 448 & 293 & 162 & 63 \\
& Плацебо & 648 & 581 & 546 & 482 & 422 & 257 & 145 & 52 \\
\hline
\end{tabular}

Рисунок 4. Динамика показателя расчетной скорости клубочковой фильтрации в исследовании CREDENCE на фоне терапии канаглифлозином 100 мг в подгруппах пациентов с различными исходными показателями (60-<90 мл/мин/1,73 м², 45-<60 мл/мин/1,73 м², $30-<45$ мл/мин/1,73 м²) [31]. 


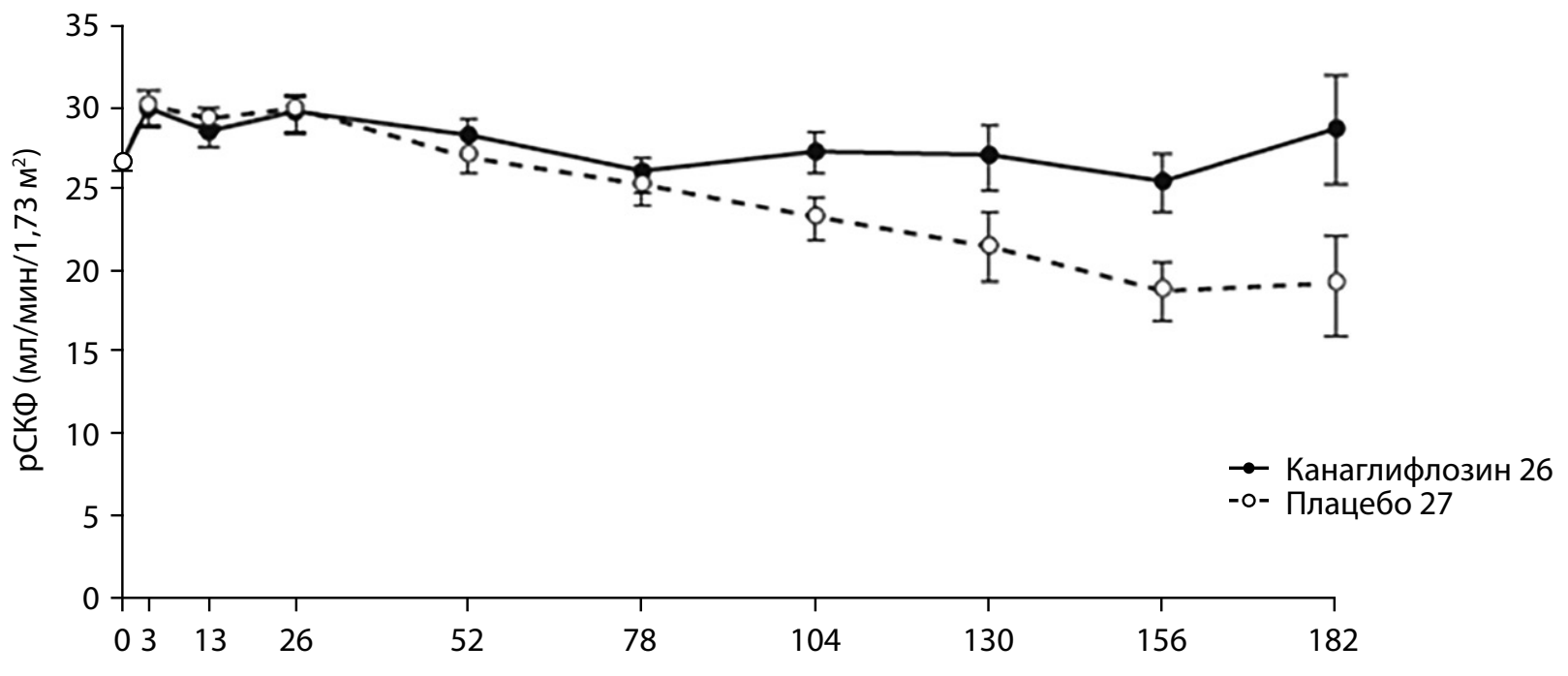

Время после рандомизации (недели)

\begin{tabular}{llllllllll}
\hline Канаглифлозин & 8282 & 77 & 78 & 71 & 57 & 50 & 36 & 22 & 7 \\
Плацебо & 8988 & 85 & 81 & 76 & 65 & 59 & 33 & 21 & 8 \\
\hline
\end{tabular}

Рисунок 5. Динамика расчетной скорости клубочковой фильтрации у пациентов с исходным значением <30 мл/мин/1,73 м² в исследовании CREDENCE. Адаптировано G. Bakris, 2020 [32].

По мере ухудшения почечной функции сахароснижающая эффективность канаглифлозина ожидаемо снижалась, однако сходное снижение выраженности альбуминурии, АД и массы тела имело место во всех подгруппах рСКФ, что иллюстрирует существование глюкозо-независимых механизмов сердечно-сосудистых и почечных эффектов глифлозинов.

Применение канаглифлозина, по сравнению с плацебо, во всех подгруппах характеризовалось меньшим числом нежелательных явлений, в том числе серьезных. При этом частота таких событий, как ампутации и переломы, также не различалась.

С учетом вышеперечисленного, а также данных наблюдательного анализа, показывающих, что по мере снижения рСКФ <30 мл/мин/1,73 м² преимущества канаглифлозина сохраняются, можно констатировать, что исследование CREDENCE заложило основу для обновления рекомендацийповедениюпациентовсСД2 ивыраженной альбуминурией, особенно при рСКФ $<45$ мл/мин/1,73 м².

Эффекты канаглифозина при СКФ <30 мл/мин/1,73 м²

Традиционно наибольшее число вопросов у клиницистов вызывает применение ингибиторов SGLT2 у пациентов с серьезно сниженной функцией почек, приближенной рСКФ к 30/мл/мин/1,73 м², особенно с учетом ожидаемого снижения ее в 1-й месяц применения на фоне ингибиторов SGLT2, с одной стороны, и ограниченных опций для лечения таких пациентов с другой.

Проф. G. Bakris выполнил post hoc-анализ данных исследования CREDENCE (ранее убедительно продемонстрировавшего нефрокардиальные преимущества применения канаглифлозина у лиц с выраженной альбуминурией и рСКФ 30-90 мл/мин/1,73 м²), оценив эффективность и безопасность применения канаглифло- зина у лиц с исходной рСКФ <30 мл/мин/1,73 м² [32]. Несмотря на то что критерием включения в CREDENCE был уровень рСКФ $\geq 30$ мл/мин/1,73 м², у части пациентов, успешно прошедших этап скрининга, в момент рандомизации была определена рСКФ ниже 30 мл/мин/1,73 м². Всего из 4401 участника (медиана наблюдения в исследовании составила 2,62 года) у 174 (4\%) пациентов при рандомизации рСКФ была ниже 30 мл/мин/1,73 м². Средняя рСКФ в этой когорте составила 35 мл/мин/1,73 м² при скрининге и 26 мл/мин/1,73 м² при рандомизации.

Динамика рСКФ в ходе исследования в этой подгруппе представлена на рис. 5.

Изменение рСКФ при инициации терапии составило к 3-й неделе 3,26 мл/мин/1,73 м² в группе применения канаглифлозина и 4,14 мл/мин/1,73 м² в группе плацебо.

В период с 3-й по 130-ю неделю исследования у лиц с исходной рСКФ менее 30 мл/мин/1,73 м² канаглифлозин показал способность замедлять темпы снижения почечной функции. Различие в средней скорости снижения рСКФ у участников, получающих канаглифлозин и плацебо, составило 66\% (среднее снижение -1,30 мл/мин/1,73 м² vs -3,83 мл/мин/1,73 м² в год, с достижением разницы между ними -2,54 мл/мин/1,73 м² в год).

У пациентов с рСКФ <30 мл/мин/1,73 м² не было выявлено различий по влиянию канаглифлозина на показатель $\mathrm{HbA}_{1 c^{\prime}}$ воздействие на показатель систолического АД также не достигло статистической значимости. Но, напротив, применение канаглифлозина сопровождалось снижением выраженности альбуминурии (соотношение А/Кр в моче было на 33\% меньше на фоне приема канаглифлозина по сравнению с плацебо). 
При этом не было выявлено дисбаланса в частоте нежелательных явлений, ассоциированных с почками, или частоте острого повреждения почек, связанного с канаглифлозином, между участниками с рСКФ <30 и $\geq 30$ мл/мин/1,73 м². Эффекты канаглифлозина на почечные, сердечно-сосудистые исходы и смертность у пациентов с рСКФ <30 и $\geq 30$ мл/мин/1,73 м² не различались. Риск развития почечной недостаточности у участников с рСКФ <30 мл/мин/1,73 м² был сопоставим с таковым у участников с РСКФ $\geq 30$ мл/мин/1,73 $\mathrm{M}^{2}$.

Таким образом, результаты данного ретроспективного анализа предполагают, что канаглифлозин замедляет прогрессирование заболевания почек, не увеличивая частоту острого повреждения почек, даже при рСКФ <30 мл/мин/1,73 м². Клиническим следствием этого является обоснование возможности для лиц с СД2 и ХБП с выраженной альбуминурией продолжать прием канаглифлозина даже при снижении рСКФ до стадии ХБП С4 не для снижения гликемии, но для оказания значимого нефропротективного эффекта. Вместе с тем впервые инициировать терапию канаглифлозином при рСКФ менее 30 мл/мин/1,73 м² по прежнему не рекомендуется.

Механизмы нефропротекции в этой ситуации менее определены, так как при рСКФ менее 30 мл/мин/1,73 м² не происходит снижения внутриклубочкового давления, что косвенно подтверждается отсутствием снижения рСКФ после инициации терапии глифлозином на сроке 0-3 нед в этом исследовании. Предполагается, что в данном случае может играть роль ингибирование симпатической нервной системы на фоне использования глифлозина, так как одним из предполагаемых механизмов хронической активации симпатической нервной системы при СД2 и артериальной гипертензии является нарушение реабсорбции натрия и глюкозы в почках $[15,33]$.

\section{Влияние канаглифлозина на развитие и течение} анемии

У пациентов с СД2 и ХБП анемия является частым осложнением ХБП, особенно по мере прогрессирования снижения СКФ [34]. Наличие анемии увеличивает риск сердечно-сосудистых и почечных осложнений, а имеющиеся средства лечения не могут повлиять на его снижение. Ингибиторы SGLT2 могут увеличивать эритропоэз и эритроцитарную массу [35].

M. Oshima и соавт. в 2020 г. провели post hoc-анализ данных исследования CREDENCE, целью которого являлось оценить долгосрочное влияние канаглифлозина на исходы, связанные с анемией [36].

Исходно средняя концентрация гемоглобина составляла 132,0 г/л. Анемия отмечалась у 1599 (36\%) из 4401 участников (Нb <130 г/л у мужчин или <120 г/л у женщин), 33 (<1\%) пациента из 4401 участника использовали средства, стимулирующие эритропоэз.

У получавших канаглифлозин пациентов через 2,6 года средняя концентрация гемоглобина была выше на 7,1 г/л, а гематокрит - выше на 2,4\%, чем в группе плацебо. В целом у 573 из 4401 участника либо был зарегистрирован случай анемии, о котором сообщал исследователь, либо было начато лечение анемии: о случаях анемии было сообщено у 358 (8\%) из 4401 участника,
343 (8\%) принимали препараты железа, 141 (3\%) - препараты, стимулирующие эритропоэз, у 114 (2\%) применялось переливание крови. Риск комбинированного исхода событий (сообщение о наличии анемии или начала антианемической терапии) был на 35\% ниже в группе канаглифлозина, чем в группе плацебо (ОР 0,65; 95\% ДИ 0,55-0,77; $p<0,0001)$. По сравнению с группой плацебо у участников группы канаглифлозина также был более низкий риск развития анемии (ОР 0,58; ДИ 0,47-0,72; $\mathrm{p}<0,0001)$, назначения препаратов железа (ОР 0,64; ДИ 0,52-0,80; $p<0,0001)$ и потребности в стимуляторах эритропоэза (ОР 0,65; ДИ 0,46-0,91; $p=0,012$ ) [36].

Таким образом, канаглифлозин показал значимое снижение риска исходов, связанных с анемией, в том числе потребности в препаратах, стимулирующих эритропоэз, у больных с СД2 и ХБП, хотя этот ретроспективный анализ и имеет определенные ограничения. К предполагаемым механизмам, которые могли бы объяснить эти эффекты, относят: возможное прямое влияние глифлозинов на эритропоэз вследствие уменьшения тубулярной гипоксии и обратимой конверсии миофибробластов в эритропоэтин-продуцирующие фибробласты; подавление гепсидина и повышение биодоступности железа; стимулирование выработки фактора HIF-1a, также стимулирующего выработку эритропоэтина и др. Кроме того, ранее в крупных РКИ по оценке влияния глифлозинов на сердечно-сосудистый риск было показано, что динамика изменений показателей гемоглобина и гематокрита была прямо связана с изменением риска ССС, СН и почечной недостаточности $[37,38]$.

\section{Влияние канаглифлозина на развитие}

гипер- и гипокалиемии

Для пациентов с ХБП, особенно имеющих выраженные стадии поражения почек, гиперкалиемия представляет собой важную клиническую проблему, особенно с учетом вовлечения в схемы терапии ингибиторов РАAC. С учетом этого в субанализе исследования CREDENCE, выполненном B. Neuen и соавт. ретроспективно была проведена оценка влияния канаглифлозина на комбинированный результат: время до развития гиперкалиемии, о которой сообщали исследователи, либо до начала приема препаратов, связывающих калий. Также было проанализировано влияние на лабораторно определяемые гипер- и гипокалиемию (калий в сыворотке $\geq 6,0$ и <3,5 ммоль/л соответственно) и изменение уровня калия в сыворотке. Исходно средний уровень калия в сыворотке в группах канаглифлозина и плацебо составлял 4,5 ммоль/л; 4395 (99,9\%) участников получали блокаду PAAC.

Частота случаев гиперкалиемии, о которой сообщали исследователи, или начала приема препаратов, связывающих калий, была ниже при приеме канаглифлозина, чем при приеме плацебо (32,7 против 41,9 участников на 1000 пациенто-лет); ОР 0,78; 95\% ДИ 0,64-0,95; $\mathrm{P}=0,014$. Канаглифлозин аналогичным образом снижал частоту развития лабораторно определяемой гиперкалиемии (ОР 0,77; 95\% ДИ 0,61-0,98; $p=0,031$ ), не влияя на риск гипокалиемии (ОР 0,92; 95\% ДИ 0,71-1,20; $\mathrm{P}=0,53$ ). Среднее значение калия в сыворотке с течением времени при применении канаглифлозина было таким же, как и при применении плацебо [39]. 
Влияние канаглифлозина на сердечную

недостаточность и сердечно-сосудистую смерть

в зависимости от исходных характеристик пациентов

$\mathrm{CH}$, СД2 и ХБП являются широко распространенными и взаимоотягощающими патологиями. В исследовании CREDENCE канаглифлозин снижал риск госпитализации по поводу $\mathrm{CH}$ или смерти от сердечно-сосудистых заболеваний (СС3) на 31\%. C. Arnott и соавт. в субанализе 2021 г. предприняли попытку определить, различалось ли влияние канаглифлозина на показатель госпитализации по поводу CH/CС-смерти в зависимости от исходных характеристик участников [40]. Было показано, что прием канаглифлозина ассоциирован со снижением ОР госпитализации по поводу СН/СС-смерти независимо от возраста, пола, наличия в анамнезе $\mathrm{CH}$ или СС3, а также применения петлевых диуретиков или агонистов рецепторов глюкагоноподобного пептида-1 (арГПП-1). При этом абсолютные преимущества применения канаглифлозина были значительно выше у пациентов с наибольшим исходным риском. Например, у пациентов с СС3 (на 50 событий меньше на 1000 пациентов, получавших лечение канглифлозином в течение 2,5 года) по сравнению с пациентами без СС3 (на 20 событий меньше). Или у пациентов с выраженными стадиями повреждения почек (при рСКФ 30-45 мл/мин/1,73 м²) предупреждается 61 событие/1000 пациентов за 2,5 года по сравнению с 23 случаями при рСКФ 60-90 мл/мин/1,73 м². Таким образом, канаглифлозин последовательно снижает пропорциональный риск госпитализаций по поводу CH/CСС в широком диапазоне подгрупп с большей абсолютной пользой у лиц с самым высоким исходным риском [40].

\section{Эффекты канаглифлозина в подгруппах}

первичной и вторичной профилактики сердечнососудистых событий

K. Mahaffey и соавт. проанализировали влияние канаглифлозина на риск сердечно-сосудистых событий в подгруппах пациентов с имеющимися АСС3 и с факторами риска их развития [41]. Участники подгруппы с факторами риска ( $\mathrm{n}=2181 ; 49,6 \%$ популяции исследования) были моложе (61 год vs 65 лет), чаще женского пола (37\% против 31\%), имели меньшую длительность СД2 (15 лет vs 16 лет) по сравнению с подгруппой пациентов с АCC3 ( $n=2220,50,4 \%$ общей популяции). Канаглифлозин снижал риск серьезных сердечно-сосудистых событий в целом (ОР 0,80; 95\% ДИ 0,67-0,95; $\mathrm{P}=0,01)$, с последовательным снижением в подгруппах как первичной (ОР 0,68; 95\% ДИ 0,49-0,94), так и вторичной профилактики (ОР 0,85; 95\% ДИ 0,69-1,06), Р для взаимодействия 0,25. Эффекты также были сходными для компонентов композитной точки, включавшей ССС (ОР 0,78; 95\% ДИ 0,61-1,00), нефатальный инфаркт миокарда (ОР 0,81; 95\% ДИ 0,59-1,10) и нефатальный инсульт (ОР 0,80; 95\% ДИ 0,56-1,15). Риск событий первичной почечной комбинированной конечной точки и комбинированной точки ССС/госпитализация по поводу $\mathrm{CH}$ последовательно снизился в группах как первичной, так и вторичной профилактики ( $р$ для взаимодействия $>0,5$ для каждого исхода).
Таким образом, в данном анализе канаглифлозин значимо снижал риск развития серьезных сердечнососудистых событий у пациентов с СД2 и ХБП, в том числе у участников, не имевших ССЗ в анамнезе.

Результаты этого субанализа имеют некоторые ограничения. Прежде всего исследование не было спланировано с достаточной статистической мощностью для оценки результатов в подгруппах, определяемых наличием/отсутствием известного СС3. Анамнез СС3 был получен по результатам анализа медицинских записей/ опроса участников, а не проведения специального обследования. Поэтому у некоторых участников группы первичной профилактики могли иметься СС3, которые не проявлялись клинически [41].

\section{ОСОБЕННОСТИ САХАРОСНИЖАЮЩЕГО ЭФФЕКТА ГЛИФЛОЗИНОВ}

Механизм сахароснижающего действия глифлозинов, обеспечивающегося ингибированием SGLT2/SGLT1 и не связанного со стимуляцией секреции инсулина, дает возможность комбинировать эту группу препаратов со всеми другими классами сахароснижающих средств [42]. В связи с инсулиннезависимым принципом действия для глифлозинов характерны низкий риск гипогликемий и сохранение сахароснижающего потенциала независимо от длительности СД2 и возраста пациента, однако мощность сахароснижающего потенциала ослабляется по мере ухудшения почечной функции и снижения СКФ [43]. С этих позиций из зарегистрированных в РФ препаратов некоторые преимущества имеет канаглифлозин, так как в связи с относительно низким соотношением селективности SGLT2/SGLT1 в определенных условиях может быть задействовано и ингибирование всасывания глюкозы в кишечнике и оказываться дополнительный глюкозурический эффект посредством ингибирования SGLT1 в почечных канальцах.

В исследовании на здоровых добровольцах было показано, что канаглифлозин в дозе 300 мг временно ингибирует абсорбцию глюкозы в кишечнике в первые 2 ч после приема пищи, за счет чего происходит снижение постпрандиального пика гликемии [44]. Прием канаглифлозина по сравнению с плацебо обеспечивал снижение постпрандиального повышения глюкозы в плазме и инсулина в период от 0 до 2 ч на 35 и 43\% соответственно $(\mathrm{P}<0,001)$, увеличение экскреции глюкозы с мочой

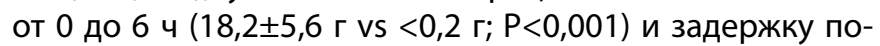
явления пероральной глюкозы в плазме на $31 \%$ в течение 0-1 ч ( $<<0,001)$ и на 20\% в течение 0-2 ч ( $p=0,002)$. В целом показано, что канаглифлозин снижает уровень постпрандиальной глюкозы и инсулина в плазме за счет увеличения экскреции глюкозы с мочой (ингибирование почечной реабсорбции глюкозы) и задержки появления пероральной глюкозы в плазме (вероятно, из-за ингибирования кишечного SGLT1).

У пациентов с СД2 прямых сравнений сахароснижающей эффективности глифлозинов не проводилось. B сетевом метаанализе F. Zaccardi (38 исследований, 23997 участников) при сравнении эффективности канаглифлозина, эмпаглифлозина, дапаглифлозина и плацебо было показано, что канаглифлозин в дозе 300 мг может снижать $\mathrm{HbA}_{1 c}$ и глюкозу плазмы натощак в большей 
степени по сравнению с другими ингибиторами в любой дозе. В самых высоких дозах канаглифлозин 300 мг снижал $\mathrm{HbA}_{1 c}$ на 0,2\% (95\% ДИ 0,1-0,3) по сравнению с дапаглифлозином 10 мг и эмпаглифлозином 25 мг [45].

\section{НЕКОТОРЫЕ ВОПРОСЫ БЕЗОПАСНОСТИ}

Одним из обсуждаемых аспектов безопасности применения глифлозинов долгое время являлся вопрос возможного увеличения риска ампутаций нижних конечностей для канаглифлозина, сигнал о котором был получен в исследовании CANVAS. Более ни в одном исследовании таких данных получено не было, а результаты исследования CREDENCE, аккумулировавшего пациентов очень высокого риска, также не подтвердили этих опасений. Систематический обзор и метаанализ 15 РКИ (совокупная популяция 63718 пациентов) также не показал значимых различий в частоте событий (ампутации) при использовании различных типов ингибиторов SGLT2, различных популяциях больных и различной длительности использования ингибиторов SGLT2 [46].

\section{ОБНОВЛЕНИЕ ТЕРАПЕВТИЧЕСКИХ АЛГОРИТМОВ ДЛЯ ПАЦИЕНТОВ С СД2 И ХБП В 2021 Г.}

За последние несколько лет препараты группы ингибиторов SGLT2 постоянно расширяют присутствие в схемах, предлагаемых для лечения пациентов СД2 с СН, ХБП, ACC3 и факторами риска АСС3 различными профессиональными ассоциациями $[42,43,47-49]$.

По сравнению с 9-м (2019 г.) выпуском «Алгоритмов специализированной медицинской помощи больным сахарным диабетом» Российской ассоциации эндокринологов, в 10-м, дополненном, выпуске (2021 г.) в разделах, затрагивающих терапию пациентов с ХБП, нашли свое отражение данные исследований, рассмотренные выше, и позиции глифлозинов усилились $[42,47]$.

В разделах, посвященных терапии ХБП, глифлозины занимают следующие позиции.

Применение ингибиторов SGLT2 как приоритетных препаратов (ранее ограниченных стадией ХБП СЗа) расширено до стадий ХБП 36-5 с учетом инструкционных ограничений по рСКФ, однако приоритет использования препаратов различен.

При наличии выраженной альбуминурии (>30 мг/ммоль) на всех стадиях ХБП к препаратам 1-й линии относят ингибиторы SGLT2 с доказанными свойствами замедлять прогрессирование ХБП в этой популяции (канаглифлозин, дапаглифлозин). Ко 2-й линии в этой популяции больных с ХБП относят глифлозины, показавшие ренальные преимущества в крупных исследованиях по оценке сердечно-сосудистого риска сахароснижающих препаратов (эмпаглифлозин, эртуглифлозин), что совпадает и с позицией Американской диабетической ассоциации [43]. На основании результатов исследований CREDENCE и DAPA-CKD в 2021 г. регуляторными органами для канаглифлозина и для дапаглифлозина были зарегистрированы новые показания по нефропротекции. Согласно обновленным инструкциям к применению этих медицинских препаратов, у пациентов, уже получавших эти средства на стадии ХБП С36, при прогрессирующем снижении СКФ появляется возможность продолжать их прием с целью нефропротекции вплоть до наступления необходимости проведения диализа (на диализе прием противопоказан). К препаратам 2-й линии относят глифлозины, показавшие ренальные преимущества в крупных исследованиях по оценке сердечно-сосудистого риска сахароснижающих препаратов.

У пациентов с ХБП в отсутствие выраженной альбуминурии приоритетом также является использование ингибиторов SGLT2, изученных в крупных РКИ по оценке сердечно-сосудистого риска с учетом инструкционных ограничений по рСКФ.

Также в обновленном разделе «Сравнительная эффективность, преимущества и недостатки сахароснижающих препаратов» в преимуществах отмечено, что ингибиторы SGLT2, возможно, обладают дополнительными преимуществами (снижение госпитализации по поводу СН или прогрессирования ХБП у лиц с высоким риском АССЗ), что обусловливает приоритетные позиции их использования в широкой популяции пациентов с СД 2.

Фактически использование ингибиторов SGLT2 уже стало составной частью многофакторного подхода к снижению риска осложнений СД2, который, наряду с традиционными константами (контролем гликемии, АД и липидов) стал включать использование препаратов с доказанными сердечно-сосудистыми и почечными преимуществами.

Российская ассоциация эндокринологов относит ингибиторы SGLT2, наряду с арГПП-1 к препаратам, позволяющим осуществить болезнь-модифицирующий подход к лечению. В частности, если у пациентов с СД2 и ХБП целевые значения гликемического контроля были достигнуты с использованием других средств, следует рассмотреть возможность включения в схему лечения препаратов из групп арГПП-1 или ингибиторов SGLT2 с подтвержденными преимуществами, заменив ими иные препараты.

Иллюстрацией важности включения препаратов с доказанными кардио- и нефропротективными эффектами в схемы лечения соответствующих популяций пациентов с СД 2 может являться анализ M. Durkin и соавт. [50]. На основании темпов снижения рСКФ в популяции исследования CREDENCE была построена линейная модель ожидаемых различий во времени наступления необходимости проведения постоянного диализа (предполагалось как снижение рСКФ <10/мл/мин/1,73 м²). Предполагаемое время наступления потребности в проведении диализа составило 22,85 года в случае терапии канаглифлозином и 9,90 лет при терапии плацебо, что в среднем соответствует возможности отдалить наступление диализа почти на 13 лет.

Этот математический прогноз имеет определенные ограничения (он не распространяется на всех пациентов с ХБП и предполагает как минимум постоянство проводимой терапии и продолжающееся линейное снижение рСКФ). Вместе с тем для клиницистов очевиден потенциал ожидаемых преимуществ замедления прогрессирования ХБП и отдаления сроков наступления диализа. Прежде всего это возможность избежать значительного ухудшения качества жизни пациентов, уменьшить колоссальную финансовую нагрузку на систему здравоохранения, в том числе в связи с уменьшением потребности в инициации диализа и длительности его проведения. 


\section{ДОПОЛНИТЕЛЬНАЯ ИНФОРМАЦИЯ}

Финансирование работы. Данная работа проведена без привлечения дополнительного финансирования

Конфликт интересов. Сухарева О.Ю., Шамхалова М.Ш. - участники проведения РКИ CREDENC, лекторы и участники экспертных советов компаний «Мерк», «АстраЗенека», «Берингер Ингельхайм», «Астеллас Фарма». Зураева 3.Т. декларирует отсутствие потенциального и явного конфликта интересов, связанного с публикацией.
Участие авторов. Сухарева О.Ю., Зураева 3.Т., Шамхалова М.Ш. разработка концепции и дизайна статьи, сбор и обработка материала, написание и утверждение текста рукописи. Все авторы одобрили финальную версию статьи перед публикацией, выразили согласие нести ответственность за все аспекты работы, подразумевающую надлежащее изучение и решение вопросов, связанных с точностью или добросовестностью любой части работы.

\section{СПИСОК ЛИТЕРАТУРЫ | REFERENCES}

1. Schwartz SS, Epstein S, Corkey BE, et al. A Unified Pathophysiological Construct of Diabetes and its Complications. Trends Endocrinol Metab. 2017;28(9):645-655. doi: https://doi.org/10.1016/j.tem.2017.05.005

2. Gerich JE, Meyer C, Woerle HJ, Stumvoll M. Renal Gluconeogenesis. Diabetes Care. 2001;24(2):382-391. doi: https://doi.org/10.2337/diacare.24.2.382

3. Bergman H, Drury DR. The relationship of kidney function to the glucose utilization of the extra abdominal tissues. Am J Physiol Content. 1938;124(2):279-284. doi: https://doi.org/10.1152/ajplegacy.1938.124.2.279

4. Meyer C, Stumvoll M, Nadkarni V, et al. Abnormal renal and hepatic glucose metabolism in type 2 diabetes mellitus. J Clin Invest. 1998;102(3):619-624. doi: https://doi.org/10.1172/JCI2415

5. Bays H. From victim to ally: the kidney as an emerging target for the treatment of diabetes mellitus. Curr Med Res Opin. 2009;25(3):671-681. doi: https://doi.org/10.1185/03007990802710422

6. Onyango AN. Mechanisms of the Regulation and Dysregulation of Glucagon Secretion. Oxid Med Cell Longev. 2020;2020:1-9. doi: https://doi.org/10.1155/2020/3089139

7. McGuire DK, Shih WJ, Cosentino F, et al. Association of SGLT2 Inhibitors With Cardiovascular and Kidney Outcomes in Patients With Type 2 Diabetes. JAMA Cardiol. 2021;6(2):148. doi: https://doi.org/10.1001/jamacardio.2020.4511

8. Zhang J, Wei J, Jiang S, et al. Macula Densa SGLT1-NOS1Tubuloglomerular Feedback Pathway, a New Mechanism for Glomerular Hyperfiltration during Hyperglycemia. J Am Soc Nephrol. 2019;30(4):578-593. doi: https://doi.org/10.1681/ASN.2018080844

9. Carlström M. The Other Glucose Transporter, SGLT1 - Also a Potential Trouble Maker in Diabetes? J Am Soc Nephrol. 2019;30(4):519-521. doi: https://doi.org/10.1681/ASN.2019020171

10. Cinti F, Moffa S, Impronta F, et al. Spotlight on ertugliflozin and its potential in the treatment of type 2 diabetes: evidence to date. Drug Des Devel Ther. 2017;11:2905-2919. doi: https://doi.org/10.2147/DDDT.S114932

11. Kashiwagi A, Maegawa H. Metabolic and hemodynamic effects of sodium-dependent glucose cotransporter 2 inhibitors on cardio-renal protection in the treatment of patients with type 2 diabetes mellitus. J Diabetes Investig. 2017;8(4):416-427. doi: https://doi.org/10.1111/jdi.12644

12. Thomas MC, Cherney DZI. The actions of SGLT2 inhibitors on metabolism, renal function and blood pressure. Diabetologia. 2018;61(10):2098-2107. doi: https://doi.org/10.1007/s00125-018-4669-0

13. Zelniker TA, Braunwald E. Cardiac and Renal Effects of SodiumGlucose Co-Transporter 2 Inhibitors in Diabetes. J Am Coll Cardiol. 2018;72(15):1845-1855. doi: https://doi.org/10.1016/j.jacc.2018.06.040

14. Heerspink HJL, Kosiborod M, Inzucchi SE, Cherney DZI. Renoprotective effects of sodium-glucose cotransporter-2 inhibitors. Kidney Int. 2018:94(1):26-39. doi: https://doi.org/10.1016/j.kint.2017.12.027

15. Салухов В.В., Халимов Ю.Ш., Шустов С.Б., Попов С.И. Ингибиторь SGLT2 и почки: механизмы и основные эффекты у больных сахарным диабетом 2 типа // Сахарный диабет. - 2020. T. 23. — № 5. - C. 475-491. [Salukhov V V, Khalimov YS, Shustov SB, Popov SI. SGLT2 inhibitors and kidneys: mechanisms and main effects in diabetes mellitus patients. Diabetes mellitus. 2021;23(5):475-491. (In Russ.)]. doi: https://doi.org/10.14341/DM12123

16. Шестакова М.В., Сухарева О.Ю. Глифлозины: особенности сахароснижающего действия и негликемические эффекты нового класса препаратов // Клиническая фармакология и терапия. -
2016. - T. 25. - № 2. - C. 65-71. [Shestakova MV, Sukhareva OYu. Gliflozins: glucose-lowering and nonglycemic effects of new class of antidiabetic medications. Clin. Pharmacol. Ther. 2016;25(2):65-71. (In Russ.)].

17. Cherney DZI, Perkins BA, Soleymanlou N, et al. Renal Hemodynamic Effect of Sodium-Glucose Cotransporter 2 Inhibition in Patients With Type 1 Diabetes Mellitus. Circulation. 2014;129(5):587-597. doi: https://doi.org/10.1161/CIRCULATIONAHA.113.005081

18. Heerspink HJL, Desai M, Jardine M, et al. Canagliflozin Slows Progression of Renal Function Decline Independently of Glycemic Effects. J Am Soc Nephrol. 2017;28(1):368-375. doi: https://doi.org/10.1681/ASN.2016030278

19. Yaribeygi H, Butler AE, Atkin SL, et al. Sodium-glucose cotransporter 2 inhibitors and inflammation in chronic kidney disease: Possible molecular pathways. J Cell Physiol. 2019;234(1):223-230. doi: https://doi.org/10.1002/jcp.26851

20. Tonneijck L, Muskiet MH, Smits MM, et al. Glomerular Hyperfiltration in Diabetes: Mechanisms, Clinical Significance, and Treatment. J Am Soc Nephrol. 2017;28(4):1023-1039. doi: https://doi.org/10.1681/ASN.2016060666

21. Wanner C, Inzucchi SE, Lachin JM, et al. Empagliflozin and Progression of Kidney Disease in Type 2 Diabetes. N Engl J Med 2016;375(4):323-334. doi: https://doi.org/10.1056/NEJMoa1515920

22. Zinman B, Wanner C, Lachin JM, et al. Empagliflozin, Cardiovascular Outcomes, and Mortality in Type 2 Diabetes. NEng/ J Med. 2015;373(22):2117-2128. doi: https://doi.org/10.1056/NEJMoa1504720

23. Neal B, Perkovic V, Mahaffey KW, et al. Canagliflozin and Cardiovascular and Renal Events in Type 2 Diabetes. N Engl J Med. 2017;377(7):644-657. doi: https://doi.org/10.1056/NEJMoa1611925

24. Wiviott SD, Raz I, Bonaca MP, et al. Dapagliflozin and Cardiovascular Outcomes in Type 2 Diabetes. N Eng/ J Med. 2019;380(4):347-357. doi: https://doi.org/10.1056/NEJMoa1812389

25. Cherney DZI, Charbonnel B, Cosentino F, et al. Effects of ertugliflozin on kidney composite outcomes, renal function and albuminuria in patients with type 2 diabetes mellitus: an analysis from the randomised VERTIS CV trial. Diabetologia. 2021;64(6):1256-1267. doi: https://doi.org/10.1007/s00125-021-05407-5

26. Zelniker TA, Wiviott SD, Raz I, et al. SGLT2 inhibitors for primary and secondary prevention of cardiovascular and renal outcomes in type 2 diabetes: a systematic review and meta-analysis of cardiovascular outcome trials. Lancet. 2019;393(10166):31-39. doi: https://doi.org/10.1016/S0140-6736(18)32590-X

27. Perkovic V, Jardine MJ, Neal B, et al. Canagliflozin and renal outcomes in type 2 diabetes and nephropathy. N Engl $\mathrm{J}$ Med. 2019;380:2295-2306. doi: https://doi.org/10.1056/NEJMoa1811744

28. Brenner BM, Cooper ME, de Zeeuw D, et al. RENAAL Study Investigators. Effects of losartan on renal and cardiovascular outcomes in patients with type 2 diabetes and nephropathy. N Eng/ J Med. 2001;345(12):861-869. doi: https://doi.org/10.1056/NEJMoa011161

29. Lewis EJ, Hunsicker LG, Clarke WR, et al. Collaborative Study Group. Renoprotective effect of the angiotensin-receptor antagonist irbesartan in patients with nephropathy due to type 2 diabetes. N Engl J Med. 2001;345(12):851-860. doi: https://doi.org/10.1056/NEJMoa011303

30. Heerspink HJL, Stefánsson BV, Correa-Rotter R, et al. DAPA-CKD Trial Committees and Investigators. Dapagliflozin in Patients with Chronic Kidney Disease. N Engl J Med. 2020;383(15):1436-1446. doi: https://doi.org/10.1056/NEJMoa2024816 
31. Jardine MJ, Zhou Z, Mahaffey KW, et al. CREDENCE Study Investigators. Renal, Cardiovascular, and Safety Outcomes of Canagliflozin by Baseline Kidney Function: A Secondary Analysis of the CREDENCE Randomized Trial. J Am Soc Nephrol. 2020;31(5):1128-1139. doi: https://doi.org/10.1681/ASN.2019111168

32. Bakris $\mathrm{G}$, Oshima M, Mahaffey KW, et al. Effects of Canagliflozin in Patients with Baseline eGFR $<30 \mathrm{ml} / \mathrm{min}$ per $1.73 \mathrm{~m}(2)$ : Subgroup Analysis of the Randomized CREDENCE Trial. Clin J Am Soc Nephrol. 2020;15(12):1705-1714. doi: https://doi.org/10.2215/CJN.10140620

33. Herat LY, Magno AL, Rudnicka C, et al. SGLT2 Inhibitor-Induced Sympathoinhibition. JACC Basic to Trans/ Sci. 2020;5(2):169-179. doi: https://doi.org/10.1016/j.jacbts.2019.11.007

34. El-Achkar TM, Ohmit SE, Mccullough PA, et al. Higher prevalence of anemia with diabetes mellitus in moderate kidney insufficiency: The Kidney Early Evaluation Program. Kidney Int. 2005;67(4):1483-1488. doi: https://doi.org/10.1111/j.1523-1755.2005.00226.x

35. Lambers Heerspink HJ, de Zeeuw D, Wie $L$, et al. Dapagliflozin a glucose-regulating drug with diuretic properties in subjects with type 2 diabetes. Diabetes Obes Metab. 2013;15(9):853-862 doi: https://doi.org/10.1111/dom.12127

36. Oshima M, Neuen BL, Jardine MJ, et al. Effects of canagliflozin on anaemia in patients with type 2 diabetes and chronic kidney disease: a post-hoc analysis from the CREDENCE trial. Lancet Diabetes Endocrinol. 2020;8(11):903-914 doi: https://doi.org/10.1016/S2213-8587(20)30300-4

37. Inzucchi SE, Zinman B, Fitchett D, et al. How Does Empagliflozin Reduce Cardiovascular Mortality? Insights From a Mediation Analysis of the EMPA-REG OUTCOME Trial. Diabetes Care. 2018;41(2):356-363. doi: https://doi.org/10.2337/dc17-1096

38. Li J, Neal B, Perkovic V, et al. Mediators of the effects of canagliflozin on kidney protection in patients with type 2 diabetes. Kidney Int. 2020;98(3):769-777. doi: https://doi.org/10.1016/j.kint.2020.04.051

39. Neuen BL, Oshima M, Perkovic V, et al. Effects of canagliflozin on serum potassium in people with diabetes and chronic kidney disease: the CREDENCE trial. Eur Heart J. 2021;42(48):4891-4901. doi: https://doi.org/10.1093/eurheartj/ehab497

40. Arnott C, Li JW, Cannon CP, et al. The effects of canagliflozin on heart failure and cardiovascular death by baseline participant characteristics: Analysis of the CREDENCE trial. Diabetes Obes Metab. 2021;23(7):1652-1659. doi: https://doi.org/10.1111/dom.14386

41. Mahaffey KW, Jardine MJ, Bompoint S, et al. Canagliflozin and Cardiovascular and Renal Outcomes in Type 2 Diabetes Mellitus and Chronic Kidney Disease in Primary and Secondary Cardiovascular Prevention Groups. Circulation. 2019;140(9):739-750. doi: https://doi.org/10.1161/CIRCULATIONAHA.119.042007

42. Дедов И.И., Шестакова М.В., Майоров А.Ю., и др. Алгоритмы спечиализированной медииинской помощи больным сахарным диабетом. 10-йвыпуск (дополненный). - М.: 2021. [Dedov II, Shestakova MV, Maiorov AYu, et al. Algoritmy spetsializirovannoi meditsinskoi pomoshchi bol'nym sakharnym diabetom. 10-i vypusk (dopolnennyi). Moscow: 2021. (In Russ.)]. Доступно по: https:// www.endocrincentr.ru/sites/default/files/specialists/science/clinicrecomendations/algoritmy_sd_kniga_10-y_vypusk_dopolnennyy. pdf

43. American Diabetes Association. 9. Pharmacologic Approaches to Glycemic Treatment: Standards of Medical Care in Diabetes-2021. Diabetes Care. 2021;44(S1):S111-124. doi: https://doi.org/10.2337/dc21-S009

44. Polidori D, Sha S, Mudaliar S, et al. Canagliflozin lowers postprandial glucose and insulin by delaying intestinal glucose absorption in addition to increasing urinary glucose excretion: results of a randomized, placebo-controlled study. Diabetes Care 2013;36(8):2154-2161. doi: https://doi.org/10.2337/dc12-2391

45. Zaccardi F, Webb DR, Htike ZZ, et al. Efficacy and safety of sodium-glucose co-transporter-2 inhibitors in type 2 diabetes mellitus: systematic review and network meta-analysis. Diabetes Obes Metab. 2016;18(8):783-794. doi: https://doi.org/10.1111/dom.12670

46. See RM, Teo YN, Teo YH, et al. Effects of Sodium-Glucose Cotransporter 2 on Amputation Events: A Systematic Review and Meta-Analysis of Randomized-Controlled Trials. Pharmacology. 2021:1-8. doi: https://doi.org/10.1159/000520903

47. Дедов И.И., Шестакова М.В., Майоров А.Ю. и др. Алгоритмы специализированной медицинской помощи больным сахарным диабетом: Клинические рекомендации (Вып. 9) // Сахарный диабет. - 2019. - Т. 22. - №S1. - C.1-144. [Dedov II, Shestakova MV, Mayorov AYu, et al. Standards of specialized diabetes care. Diabetes Mellitus. 2019;22(S1):1-144 (In Russ.)]. doi: https://doi.org/10.14341/DM221S1

48. Buse JB, Wexler DJ, Tsapas A, et al. 2019 Update to: Management of Hyperglycemia in Type 2 Diabetes, 2018. A Consensus Report by the American Diabetes Association (ADA) and the European Association for the Study of Diabetes (EASD). Diabetes Care. 2020:43(2):487-493. doi: https://doi.org/10.2337/dci19-0066

49. Garber AJ, Handelsman Y, Grunberger G, et al. Consensus Statement by the American Association of Clinical Endocrinologists and American College of Endocrinology on the Comprehensive Type 2 Diabetes Management Algorithm 2020 Executive Summary. Endocr Pract. 2020;26(1):107-139. doi: https://doi.org/10.4158/CS-2019-0472

50. Durkin M, Blais J. Linear Projection of Estimated Glomerular Filtration Rate Decline with Canagliflozin and Implications for Dialysis Utilization and Cost in Diabetic Nephropathy. Diabetes Ther. 202112(2):499-508 doi: https://doi.org/10.1007/s13300-020-00953-4

\section{ИНФОРМАЦИЯ ОБ АВТОРАХ [AUTHORS INFO]}

*Сухарева Ольга Юрьевна, К.M.н. [Olga Y. Sukhareva, MD, PhD]; адрес: 117036, Москва, ул. Дм. Ульянова, д. 11 [address: 11 Dm. Ulyanova str., Moscow, 117036 Russian Federation]; ORCID: https://orcid.org/0000-0002-3443-7206; eLibrary SPIN: 5650-4416; e-mail: olgasukhareva@mail.ru

Зураева Замира Тотразовна, к.M.н. [Zamira T. Zuraeva, MD, PhD]; ORCID: https://orcid.org/0000-0001-6953-6928; eLibrary SPIN: 6002-0455; e-mail: zuraeva_zamira@mail.ru Шамхалова Минара Шамхаловна, д.м.н. [Minara S. Shamhalova, MD, PhD]; ORCID: https://orcid.org/0000-0002-3433-0142; eLibrary SPIN: 4942-5481; e-mail: shamkhalova@mail.ru

\section{ЦИТИРОВАТЬ:}

Сухарева О.Ю., Зураева 3.Т., Шамхалова М.Ш. Актуализация позиций глифлозинов в алгоритмах лечения пациентов с сахарным диабетом 2 типа и хронической болезнью почек: новые патогенетические механизмы и данные субанализов крупных рандомизированных контролируемых исследований // Сахарный диабет. — 2021. — Т. 24. — №6. — C. 553-564. doi: https://doi.org/10.14341/DM12864

\section{TO CITE THIS ARTICLE:}

Sukhareva OYu, Zuraeva ZT, Shamkhalova MSh. Gliflozins position update in the treatment algorithms for patients with type 2 diabetes mellitus and chronic kidney disease: new pathogenetic mechanisms and data from subanalyses of the large randomised control trails. Diabetes Mellitus. 2021;24(6):553-564. doi: https://doi.org/10.14341/DM12864 